\title{
Prevalence and predictors of metabolic syndrome in women with polycystic ovarian syndrome: a study from Southern India
}

\author{
Jisha Varghese ${ }^{1}$, Supriya Kantharaju ${ }^{1}{ }^{*}$, Suchitra Thunga ${ }^{1}$, \\ Nitin Joseph ${ }^{2}$, Prakhar Kumar Singh ${ }^{3}$
}

\begin{abstract}
${ }^{1}$ Department of Obstetrics \& Gynecology, Kasturba Medical College, Mangalore, Manipal University, Karnataka, India

${ }^{2}$ Department of Community Medicine, Kasturba Medical College, Mangalore, Manipal University, Karnataka, India

${ }^{3}$ Student, Kasturba Medical College, Mangalore, Manipal University, Karnataka, India
\end{abstract}

Received: 28 November 2014

Accepted: 20 December 2014

\author{
*Correspondence: \\ Dr. Supriya Kantharaju, \\ E-mail: dr_ksupriya@yahoo.com
}

Copyright: (C) the author(s), publisher and licensee Medip Academy. This is an open-access article distributed under the terms of the Creative Commons Attribution Non-Commercial License, which permits unrestricted non-commercial use, distribution, and reproduction in any medium, provided the original work is properly cited.

\begin{abstract}
Background: Metabolic syndrome (MBS) is a common disorder and is thought to be highly prevalent in polycystic ovarian syndrome (PCOS). The objectives were to find out the prevalence and predictors of metabolic syndrome in women with PCOS.

Methods: Forty five women diagnosed with PCOS, underwent clinical and laboratory assessments for the diagnosis of metabolic syndrome, as per modified National Cholesterol Education Program's Adult Treatment Panel III (NCEP ATP III criteria).

Results: Twenty four (53.3\%) subjects had metabolic syndrome. The prevalence of individual components of the metabolic syndrome among PCOS patients were: waist circumference $\geq 80 \mathrm{~cm}$ in $36(86.6 \%)$, High Density Lipoprotein (HDL-C) less than $50 \mathrm{mg} / \mathrm{dl}$ in $42(93.3 \%)$, triglycerides $\geq 150 \mathrm{mg} / \mathrm{dl}$ in $17(37.8 \%)$, blood pressure $\geq 130 / 85 \mathrm{mmHg}$ in $7(15.6 \%)$, and fasting plasma glucose $\geq 100 \mathrm{mg} / \mathrm{dl}$ in $13(28.8 \%)$. Subjects with MBS had significantly higher $\mathrm{BMI}$ compared to those without $(\mathrm{P}=0.039)$. However, fasting insulin and free testosterone levels did not differ significantly between subjects with and without MBS.

Conclusions: The metabolic syndrome and its individual components, waist circumference $\geq 80 \mathrm{~cm}$ in particular were found to be common among PCOS patients in this study. This along with high BMI being significantly associated with MBS suggests immediate need of interventions like lifestyle changes for prevention of MBS and other cardiovascular diseases. Also, as dyslipidemia was more common than impaired fasting glucose among PCOS patients, finding of one risk factor should prompt the clinician to search for other risk factors.
\end{abstract}

Keywords: Polycystic ovarian syndrome, Metabolic syndrome, Ethnic specific BMI, Modified NCEP ATP III criteria

\section{INTRODUCTION}

Polycystic ovarian syndrome is a common endocrine disorder affecting about $5-8 \%$ of women in the reproductive age group. ${ }^{1}$ Its presence is a cause of concern since the patients with persistent disease are prone to develop type 2 diabetes mellitus and cardio vascular disease due to the underlying hyperinsulinemia and insulin resistance. ${ }^{2}$

The patients with PCOS may have features suggestive of metabolic syndrome (MBS) much earlier than the development of diabetes mellitus and cardiovascular disease. The metabolic syndrome, composed of lipid and 
non-lipid factors, identifies the individuals at risk of developing cardiovascular disease and type 2 diabetes mellitus due to the underlying insulin resistance. ${ }^{3,4}$ Identification of MBS in patients with PCOS early in their disease process may help in bringing the awareness and timely initiation of measures of involved life style changes.

The metabolic syndrome was codified in the National Cholesterol Education Program Adult Treatment Panel III (NCEP ATP III) guidelines. ${ }^{5}$ This definition includes fasting glucose, waist circumference, blood pressure and lipid criteria. The main changes in the modified American Heart Association/National Heart Lung and Blood Institute definition (ATP III) include 1) ethnic specific waist circumference and 2) reducing the threshold for impaired fasting glucose as per revised American Diabetes Association definition. ${ }^{4}$ The prevalence of the metabolic syndrome in women with PCOS has wide variations and it ranges from $1.6 \%{ }^{6}$ to $47 \% .^{7}$ depending upon the population studied and the criteria used for the diagnosis of the metabolic syndrome.

There are very few studies from the Indian subcontinent which have included ethnic specific waist circumference and BMI. Hence such studies which aim at estimating the prevalence of metabolic syndrome among PCOS patients in our study population become very relevant. The other objective of this study was to identify the predictors of the metabolic syndrome among these patients.

\section{METHODS}

\section{Subjects}

The study was approved by our institutional ethics committee.

An observational study was carried out in women with PCOS attending to a tertiary care teaching hospital between February 2012 and August 2012 for treatment and/ or follow-up.

The diagnosis of PCOS was based on the 2003 Rotterdam consensus. ${ }^{8}$ All willing subjects were recruited into the study after obtaining their written informed consent. Women with history of ovarian steroidal hormone therapy or insulin sensitizing agent intake in the past three months, abnormal thyroid and prolactin levels were excluded from the study.

For purpose of the study following definitions/ descriptions were followed while recruiting the cases:

- Oligo ovulation and/ or anovulation - if oligomenorrhea or amenorrhea was present.

○ Oligomenorrhea - menstrual cycles with intermenstrual intervals of $>35$ days. $\circ$ Amenorrhea - no menstruation for $>3$ months.

- Clinical hyperandrogenism - presence of hirsutism (Ferriman-Gallwey score of $\geq 8$ ) and /or acne/androgenic alopecia or biochemical record of free testosterone level was $>7 \mathrm{pg} / \mathrm{ml}$

- Polycystic ovary on ultrasound was defined as the presence of at least one ovary with 12 or more follicles measuring $2-9 \mathrm{~mm}$ in diameter and/or ovarian volume $>10 \mathrm{~cm}^{3}$ in atleast one ovary using transvaginal probe.

- Ovarian volume measurements were carried out by measuring three perpendicular dimensions.

- Follicle number was estimated both in longitudinal and antero-posterior cross sections of the ovaries.

The subject particulars, menstrual and medical history, and physical examination findings were noted on the designed format by direct questionnaire.

Presence of indicators of metabolic syndrome was considered to be significant, if any three of the following were present as per modified NCEP ATP III criteria:

1) Ethnic specific central obesity - waist circumference $\geq 80 \mathrm{~cm}$

2) Elevated systolic and or diastolic blood pressure of $\geq 130 / 85 \mathrm{mmHg}$

3) Elevated Fasting plasma glucose $\geq 100 \mathrm{mg} / \mathrm{dl}$

4) Elevated fasting serum triglycerides $\geq 150 \mathrm{mg} / \mathrm{dl}$

5) Reduced Fasting HDL-C $<50 \mathrm{mg} / \mathrm{dl}$

Waist circumference in centimeters was measured just above the hip bones at the end of expiration using a measuring tape. Height was recorded using a stadiometer to the nearest $0.1 \mathrm{~cm}$ and weight was recorded using a weighing scale to the nearest 0.5 kilograms. The Body Mass Index (BMI) was calculated in all women in addition to indicators for MBS and were categorized as per ethnic specifications ${ }^{9}$ i.e. Normal BMI as 18.0-22.9 $\mathrm{kg} / \mathrm{m}^{2}$, overweight as $23.0-24.9 \mathrm{~kg} / \mathrm{m}^{2}$ and obesity as $\geq 25$ $\mathrm{kg} / \mathrm{m}^{2}$.

Sitting blood pressure was measured after a 5-min rest using a standard sphygmomanometer and an average of two readings were considered. Fasting blood samples were obtained for the measurement of TSH, Prolactin, HDL-C, triglycerides, glucose, Insulin and free testosterone levels.

Fasting insulin $>24.9 \mu \mathrm{U} / \mathrm{ml}$ was taken as laboratory evidence of hyperinsulinemia. 


\section{Statistical analysis}

Data was entered and analyzed using SSPS version 17.0. Students unpaired t test was used to find the association between continuous variables with the presence of metabolic syndrome among the participants. The positive and negative predictive value of various individual parameters as screening tools to detect the metabolic syndrome was found by comparing with the standard criteria used for the diagnosis of the metabolic syndrome.

A $\mathrm{P}$ value $<0.05$ was taken as statistically significant association.

\section{RESULTS}

Out of the 45 patients with PCOS, 24 (53.3\%) were diagnosed with MBS. The subjects ranged in the age from $18-35$ years, with a mean age of $26.6 \pm 4.6$ years.

MBS was found in greater proportion of PCOS cases aged 31-35 years (83.3\%) followed by 21-25 years (57.9\%). However no association was found between age distributions of PCOS cases with development of metabolic syndrome $(\mathrm{P}=0.12)$ (Table 1$)$.

Table 1: Association between age of participants with development of metabolic syndrome.

\begin{tabular}{|llll|}
\hline $\begin{array}{l}\text { Age group } \\
\text { (years) }\end{array}$ & $\begin{array}{l}\text { Metabolic syndrome } \\
\text { Absent } \\
\text { n (\%) }\end{array}$ & $\begin{array}{l}\text { Present } \\
\text { n (\%) }\end{array}$ & $\begin{array}{l}\text { Total } \\
\text { (n) }\end{array}$ \\
\hline 18 to 20 & $7(77.8)$ & $2(22.2)$ & 9 \\
\hline 21 to 25 & $8(42.1)$ & $11(57.9)$ & 19 \\
\hline 26 to 30 & $5(45.5)$ & $6(54.5)$ & 11 \\
\hline 31 to 35 & $1(16.7)$ & $5(83.3)$ & 6 \\
\hline Total & $21(46.7)$ & $24(53.3)$ & 45 \\
\hline
\end{tabular}

$\mathrm{P}$ value $=0.120$

The mean BMI in the study group was $26.19 \mathrm{~kg} / \mathrm{m}^{2}$ with a range of 16.4 to $35.5 \mathrm{~kg} / \mathrm{m}^{2}$. The prevalence of the metabolic syndrome in this study was found to significantly increase with increasing BMI $(P=0.039)$ (Table 2).

Table 2: Association of body mass index with development of metabolic syndrome.

\begin{tabular}{|llll|}
\hline BMI category & $\begin{array}{l}\text { Metabolic syndrome } \\
\text { Absent } \\
\text { n (\%) }\end{array}$ & $\begin{array}{l}\text { Present } \\
\text { n (\%) }\end{array}$ & $\begin{array}{l}\text { Total } \\
\text { (n) }\end{array}$ \\
\hline Normal/underweight & $7(63.6)$ & $4(36.4)$ & 11 \\
\hline Over weight & $6(75.0)$ & $2(25.0)$ & 8 \\
\hline Obese & $8(30.8)$ & $18(69.2)$ & 26 \\
\hline Total & $21(46.7)$ & $24(53.3)$ & 45 \\
\hline
\end{tabular}

$\mathrm{P}$ value $=0.039$
The most prevalent factors among the individual components of the metabolic syndrome in PCOS patients were low HDL-C (93.3\%), followed by high waist circumference $(86.6 \%)$ and raised serum triglycerides $(37.8 \%)$ (Table 3).

Table 3: Distribution of individual components of the metabolic syndrome among study participants $(n=45)$.

\begin{tabular}{|ll|}
\hline Components of MBS & $\begin{array}{l}\text { Total No. } \\
\text { n }(\%)\end{array}$ \\
\hline Waist circumference & $36(86.6)$ \\
\hline Hypertension & $7(15.6)$ \\
\hline HDL-C & $42(93.3)$ \\
\hline Triglycerides & $17(37.8)$ \\
\hline Fasting glucose & $13(28.8)$ \\
\hline
\end{tabular}

Analysis of physical (BMI, MFG) and biochemical parameters (fasting Insulin and free testosterone levels) in predicting the underlying biochemical derangement to suggest MBS showed that maximum sensitivity was for MFG score (95.8\%) followed by BMI (83.3\%). However specificity was found to be maximum with fasting Insulin (100\%) followed by BMI (33.3\%).

Hirsutism was present in $43(95.5 \%)$ patients. Serum free testosterone levels were within the normal range irrespective of the status of developing metabolic syndrome among PCOS cases (Table 4).

Table 4: Validity of BMI, fasting insulin levels and MFG scores for screening MBS.

\begin{tabular}{|llll|} 
Determinants & $\begin{array}{l}\text { Metabolic syndrome } \\
\text { Present } \\
\text { n (\%) }\end{array}$ & $\begin{array}{l}\text { Absent } \\
\text { n (\%) }\end{array}$ & Total \\
\hline BMI category & & & \\
\hline Underweight/ normal & $4(36.4)$ & $7(63.6)$ & 11 \\
\hline Overweight/ obese & $20(58.8)$ & $14(41.2)$ & 34 \\
\hline Fasting insulin & & & \\
\hline Normal & $22(51.2)$ & $21(48.8)$ & 43 \\
\hline Raised & $2(100)$ & 0 & 2 \\
\hline MFG score & & & \\
\hline Raised & $23(53.5)$ & $20(46.5)$ & 43 \\
\hline Normal & $1(50.0)$ & $1(50.0)$ & 2 \\
\hline Total & $24(53.3)$ & $21(46.7)$ & 45 \\
\hline
\end{tabular}

\section{DISCUSSION}

The metabolic syndrome identifies the individuals who are at risk of developing type 2 diabetes mellitus and cardiovascular disease in women with PCOS. ${ }^{3,4}$

In the present study, more than one half of the patients fulfilled the criteria for the diagnosis of the metabolic syndrome at an younger age ( $<35$ years). This was higher than the prevalence of $42 \%$ by NCEP ATP III criteria, ${ }^{10}$ $47.4 \%$ by IDF criteria, ${ }^{11} 37.5 \%$ by modified NCEP ATP III criteria ${ }^{12}$ reported in various Indian studies and of 
$47.3 \%{ }^{7}$ and $43 \%{ }^{13}$ observed in studies done in USA. Differences in the prevalence of MBS in different parts of the world could be due to variations in the population studied and also because of different criteria used for diagnosing MBS. This higher prevalence of MBS in the present study can be attributed to higher prevalence of obesity in the study population. This emphasizes the need for life style modification and change in dietary habits to prevent obesity and occurrence of MBS. In the present study the ethnic specific BMI was used for the categorization. This was because of studies reporting excess morbidity risk of Asians at lower BMI values, as compared with other ethnic groups. ${ }^{9}$ The criteria for stating obesity based on BMI $>25 \mathrm{~kg} / \mathrm{m}^{2}$ used in this study would be comparable to BMI $>30 \mathrm{~kg} / \mathrm{m}^{2}$ for Americans and hence could justify the finding of higher prevalence of metabolic syndrome as observed. This finding of increased prevalence of the metabolic syndrome at lower BMI endorse the fact that south Asians/Indians have more body fat in spite of the same BMI as compared with the western population ${ }^{14}$ and hence the recommended cut off BMI for healthy urban Asians is $<23 \mathrm{~kg} / \mathrm{m}^{2}{ }^{15}$ European studies on the contrary reported the prevalence of metabolic syndrome to be low. It was $1.6 \%$ in the Czech Republic, ${ }^{6} 2.3 \%$ in Turkey, ${ }^{16}$ and ranged from $8.2 \%$ to $16 \%$ in southern Italy. ${ }^{17}$ This was attributed to the lower prevalence of obesity (BMI $>30 \mathrm{~kg} / \mathrm{m}^{2}$ ) in the study population, which was determined genetically and modified by the lifestyle factors. Thus high BMI can significantly influence the likelihood of having the MBS, the finding similar to many studies. ${ }^{13,18}$

In the present study, the average BMI in both the groups was above the recommended ethnic specific cut off value. Those with the metabolic syndrome had much higher BMI compared to those without the MBS. Among the patients with MBS more than three fourths had BMI $>23$ $\mathrm{kg} / \mathrm{m}^{2}$.

The prevalence of the individual components of the metabolic syndrome differs significantly depending on the race studied. ${ }^{19}$ For example, in the United States, ${ }^{13}$ the most prevalent components were low HDL-C (68\%) followed by elevated BMI (67\%). In this study it was low HDL-C (93.3\%) followed by high WC (86.6\%).

In a study done in Kolkata, India, the most prevalent components were low HDL-C (50\%) and hypertension $(50 \%) .{ }^{10}$ This difference compared to our findings could be due to the differences in the dietary habits. Factors responsible for intra ethnic differences in the various indicators of the metabolic syndrome thus need further studies, in the light of these findings. In further evaluating the MBS in PCOS, it was found that women with PCOS had at least one abnormality of the MBS. The low HDL-C being the most common lipid abnormality probably reflects the sedentary life style and intake of diet rich in saturated fat in the present study population.
Our study demonstrated that while metabolic abnormality was often seen in overweight/obese women, even lean women had dyslipidemia. Our finding supports the view that even though obesity worsens the insulin resistance in women with PCOS, even lean PCOS have features of insulin resistance. ${ }^{20,21}$

Eighteen patients (40\%) with PCOS had both lipid abnormalities in comparison to thirteen patients (28.8\%) who had elevated fasting plasma glucose. The main drawback of using FPG alone without Oral Glucose Tolerance Test (OGTT) as one of the diagnostic criteria in ATPIII, is that it underestimates the diabetes and cardiovascular risks among obese patients. ${ }^{22,23}$

Knowing the fact that Asia is diabetic hub, fasting glucose underestimates the prevalence of diabetes. Hence OGTT would be required in these women as a complementary test.

The high prevalence of lipid abnormalities as compared to glucose abnormality emphasizes the need for dyslipidemia screening, rather than FPG alone, in women with PCOS.

Many studies have found a significant association between fasting insulin levels and metabolic syndrome, ${ }^{7,10,18}$ however in our study we found no significant association between them. The reason for this is not known.

Another contributing factor to cardiovascular disease is hyperandrogenemia. Some studies found significant association between free testosterone levels and the metabolic syndrome. ${ }^{12,13}$ However, in this study and the observations of Dokras et al. ${ }^{7}$ no such association was seen. In the present study free testosterone levels were within the normal range, but hirsutism was seen in $86.6 \%$. This could be because of the difference in the sensitivity of the hair follicles to the circulating androgens, determined by racial factors.

Remprasad D et al. found an association between metabolic syndrome and young PCOS patients which was again different from our findings. ${ }^{10}$

Further studies with a large sample size and control group, matched for age and BMI would be required to determine the independent effects of PCOS on metabolic abnormality in our population.

We would recommend that women with central obesity/ BMI $>23 \mathrm{~kg} / \mathrm{m}^{2}$, should be screened for metabolic syndrome.

\section{There were some limitations to our study}

This study was done among a small sample of PCOS patients reporting to a tertiary care hospital over a specified time period. Despite this limitation, the findings of this study have significant clinical implications as 
these women were not preselected. Rather they represent PCOS patients managed in a clinical practice.

\section{CONCLUSIONS}

Metabolic syndrome was seen in more than half of PCOS cases and more than half of the patients with MBS were aged 25 years or below. This highlights the need for comprehensive screening and educational programs for women with PCOS beginning at an early age.

But as screening all women with PCOS for MBS would not be practical in a low resource country like India, identifying the risk factors among these young women with PCOS would be an alternative strategy. We would recommend that women with central obesity/BMI $>23$ $\mathrm{kg} / \mathrm{m}^{2}$ among PCOS cases to be screened for metabolic syndrome.

As lipid abnormalities were seen more commonly than plasma glucose abnormality in MBS patients, screening of other parameters in addition to commonly done investigations need to be practiced by clinicians.

Whenever patients present with history of menstrual irregularities, cosmetic problems or subfertility to the gynecologist, if screening for the metabolic syndrome is also done along with the routine evaluative procedures for PCOS, this will go a long way in preventing or delaying type 2 diabetes and cardiovascular diseases.

\section{List of abbreviations used}

PCOS - Polycystic ovarian syndrome

MBS - Metabolic syndrome

HDL-C - High density lipoprotein- cholesterol

WC - Waist circumference

FPG - Fasting plasma glucose

\section{Funding: No funding sources}

Conflict of interest: None declared

Ethical approval: The study was approved by the institutional ethics committee

\section{REFERENCES}

1. Azziz R, Woods KS, Reyna R, Key TJ, Knochenhauer ES, Yildiz BO. The prevalence and features of the polycystic ovary syndrome in an unselected population. J Clin Endocrinol Metabol. 2004;89(6):2745-9.

2. Probstfield JL, Byington RP, Egan DA, Espeland MA, Margitic SE, Riley WA Jr, et al. Methodological issues facing studies of atherosclerotic changes. Circulation. 1993;87:117481.

3. DeFronzo RA, Ferrannini E. Insulin resistance. A multifaceted syndrome responsible for NIDDM, obesity, hypertension, dyslipidemia and atherosclerotic cardiovascular disease. Diabetes Care. 1991;14:173-94.

4. Grundy SM, Cleeman JL, Daniels SR, Donato KA, Eckel RH, Franklin BA, et al. Diagnosis and management of the metabolic syndrome: an American Heart Association/National Heart, Lung and Blood Institute Scientific Statement. Circulation. 2005; 112:2735-52.

5. Third report of the National Cholesterol Education Program (NCEP). Expert panel on detection, evaluation and treatment in high blood cholesterol in adults (Adult Treatment Panel 111) final report. Circulation. 2002;106(25):3143-421.

6. Vrbikova J, Vondra K, Cibula D, Dvoráková K, Stanická S, Srámková D, et al. Metabolic syndrome in young Czech women with polycystic ovary syndrome. Hum Reprod. 2005;20:3328-32.

7. Dokras A, Bochner M, Hollinrake E, Markham S, Vanvoorhis B, Jagasia DH. Screening women with polycystic ovary syndrome for metabolic syndrome. Obstet Gynecol. 2005;106:131-7.

8. The Rotterdam ESHRE/ASRM, Sponsored PCOS Consensus Workshop Group. Revised 2003 consensus on diagnostic criteria and long term health risks related to polycystic ovary syndrome. Fertil Steril. 2004;81:19-25.

9. World Health Organization. International association for the study of international obesity task force. The Asia-Pacific perspective redefining obesity and its treatment, 2000. Available at: http://www.wpro.who.int/nutrition/documents/Redefi ning_obesity/en/.

10. Dey R, Mukherjee S, Roybiswas R, Mukhopadhyay A, Biswas SC. Association of metabolic syndrome in polycystic ovarian syndrome: an observational study. J Clin Obstet Gynecol India. 2011 Mar/Apr;61(2):176-81.

11. Bhattacharya SM. Metabolic syndrome in females with polycystic ovary syndrome and International Diabetes Federation Criteria. J Obstet Gynecol. 2008;34:62-6.

12. Mandrelle K, Mohan SK, Bondu DJ, Chandy A, Aleyamma T, George K. Prevalence of metabolic syndrome in women with polycystic ovary syndrome attending an infertility clinic at a tertiary care hospital in south India. J Hum Reprod Sci. 2012 JanApr;5(1):26-31.

13. Apridonidze T, Essah PA, Iuorno MJ, Nestler JE. Prevalence and characteristics of the metabolic syndrome in women with polycystic ovarian syndrome. J Clin Endocrinol Metabol. 2005;90:1929-35.

14. Mckeigue PM, Shah B, Marmott MG. Relationship of central obesity and insulin resistance with high diabetes prevalence and cardiovascular risk in South Asians. Lancet. 1991;337:382-6.

15. SnehalathaC, Vishwanathan V, Ramachandran A. Cutoff values for normal anthropometric variables in Asian Indian adults. Diabetes Care. 2003;26:1380-4. 
16. Vural B, Caliskan E, Turkoz E, Kilic T, Demirei A. Evaluation of metabolic syndrome frequency and premature carotid atherosclerosis in young women with polycystic ovary syndrome. Hum Reprod. 2005;9:2409-13.

17. Carmina E, Napoli N, Longo RA, Rini GB, Lobo RA. Metabolic syndrome in polycystic ovary syndrome: lower prevalence in southern Italy than in the USA and the influence of criteria for the diagnosis of PCOS. Eur J Endocrinol. 2006;154:1415.

18. Glueck CJ, Papanna R, Wang P, Goldenberg N, Sieve-Smith L. Incidence and treatment of metabolic syndrome in newly referred women with confirmed polycystic ovarian syndrome. Metabolism. 2003;52:908-15.

19. Ehrmann DA, Liljenquist DR, Kasza K, Azziz R, Legro RS, Ghazzi MN, et al. Prevalence and predictors of the metabolic syndrome in women with polycystic ovary syndrome. J Clin Endocrinol Metabol. 2006;91(1):48-53.

20. Dunaif A. Insulin resistance and the polycystic ovary syndrome: mechanism and implications for pathogenesis. Endocr Rev. 1997;18:774-800.
21. Dunaif A, Segal KR, Futterweit W, Dobrjansky A. Profound peripheral insulin resistance, independent of obesity, in polycystic ovary syndrome. Diabetes. 1989;38: 1165-74.

22. Ehrmann DA, Barnes RB, Rosenfield RL, Cavaghan MK, Imperial J. Prevalence of impaired glucose tolerance and diabetes in women with polycystic ovary syndrome. Diabetes Care. 1999;22:141-6.

23. Janus ED, Watt NM, Lam KS, Cockram CS, Siu ST, Liu LJ, et al. The Prevalence of diabetes, association with cardiovascular risk factors and implications of diagnostic criteria (ADA 1997 and WHO 1998) in a 1996 community-based population study in Hong Kong Chinese. Hong Kong Cardiovascular Risk Factor Steering Committee. American Diabetes Association. Diabet Med. 2000;17:741-5.

DOI: $10.5455 / 2320-1770$. ijrcog20150222

Cite this article as: Varghese $\mathrm{J}$, Kantharaju S, Thunga S, Joseph N, Singh PK. Prevalence and predictors of metabolic syndrome in women with polycystic ovarian syndrome: a study from Southern India. Int J Reprod Contracept Obstet Gynecol 2015;4:113-8. 